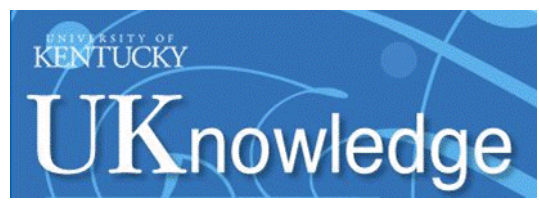

University of Kentucky

UKnowledge

$1-2003$

\title{
Sex Education in the Schools: What Role Does it Play?
}

\author{
Darby H. McElderry \\ University of Kentucky \\ Hatim A. Omar \\ University of Kentucky, hatim.omar@uky.edu
}

Follow this and additional works at: https://uknowledge.uky.edu/pediatrics_facpub

Part of the Education Commons, and the Pediatrics Commons

Right click to open a feedback form in a new tab to let us know how this document benefits you.

\section{Repository Citation}

McElderry, Darby H. and Omar, Hatim A., "Sex Education in the Schools: What Role Does it Play?" (2003). Pediatrics Faculty Publications. 81.

https://uknowledge.uky.edu/pediatrics_facpub/81

This Article is brought to you for free and open access by the Pediatrics at UKnowledge. It has been accepted for inclusion in Pediatrics Faculty Publications by an authorized administrator of UKnowledge. For more information, please contact UKnowledge@lsv.uky.edu. 


\section{Sex Education in the Schools: What Role Does it Play?}

Digital Object Identifier (DOI)

http://dx.doi.org/10.1515/IJAMH.2003.15.1.3

Notes/Citation Information

Published in International Journal of Adolescent Medicine and Health, v. 15, no. 1, p. 3-9.

(c) Freund Publishing House Ltd.

The copyright holder has granted permission for posting the article here.

Reprinted as a book chapter in Adolescent Behavior Research: International Perspectives. Joav Merrick, \& Hatim A. Omar, (Eds.). p. 101-108.

This article is available at UKnowledge: https://uknowledge.uky.edu/pediatrics_facpub/81 


\title{
Sex education in the schools: What role does it play?
}

\author{
Darby H McElderry, MD and Hatim A Omar, MD
}

Department of Pediatrics and Adolescent Medicine, University of Kentucky Medical Center, Lexington, KY, United States of America

Abstract: Information regarding pubertal development, sex, pregnancy, and contraception should be provided to children and adolescents in an age-appropriate manner from parents, health care providers, and schools. This article reviews the medical literature on school sex edication programs, adolescents' perception of these programs, and the role played by the media, parents, and health care professionals in sexual education of teens.

Keywords: sex education, schools, United States

Correspondence: Associate professor Hatim A Omar, MD, Department of Pediatrics and Adolescent Medicine, University of Kentucky Medical Center, Lexington, KY, United States of America. Tel: 859-3236426 ext 307, Fax: 859-257 7706, E-mail: haomar2@pop.uky.edu

Submitted: August 28, 2002. Revised:August 30, 2002. Accepted: September 01, 2002.

\section{INTRODUCTION}

In its policy statement in 2000 on school health assessments, the American Academy of Pediatrics recommended that information/anticipatory guidance should be provided during comprehensive health examinations (1). While some might like to ignore issues about sex and adolescents altogether, numbers in the literature show us why it is mandatory to address these issues. Although the teen birth rate has been declining in recent years, the United States continues to lead Western nations, estimated at 80 per 1,000 females aged 15 to 19 years (2). Studies have shown this is not because American teens are having sex in greater numbers than teens in other countries (3), but might be linked to inadequate information about contraception or lack of access to contraception. By the twelfth grade, greater than $60 \%$ of adolescents have had sex, with $45.6 \%$ of high school age students reporting having ever been sexually active (4). However, only $58 \%$ of teens report using condoms at last sexual encounter, a number that held steady from 2000 to 2001 (4). Nationally, $6.8 \%$ of teens report initiation of sexual intercourse prior to 13 years of age. $14.2 \%$ of teens in the 2001 Youth Risk Behavior Survey (YRBS) reported greater than or equal to four lifetime sexual partners. From 1999 to 2001, there was a significant decrease in those who had ever had sex (from $54.1 \%$ to $45.6 \%$ ) as well as decrease in those with greater than four lifetime partners (from 18.7 to $14.2 \%$ ). "

Teens get information about sex and pubertal development from many sources, including peers, parents, the media, school sex education, and health care professionals. Information regarding sex and its health-related consequences obtained from peers and the media might not always be accurate, so the duty falls on parents, health care professionals and the schools. These should strive to provide complete and comprehensive information about sex, sexually transmitted infections (STIs), pregnancy and its health risks, contraception options, emotional and psychological concerns related to sex, and the benefits of abstinence.

Most schools, beginning at the middle or junior high school level, include some form of sex education in their health class 
curriculum. The content of such curricula varies widely, however, and there seems to be a trend towards abstinence-only based education in the schools in recent years. In one survey, teachers were more likely in 1999 than those in 1988 to cite abstinence as the most important message they wished to convey ( $41 \%$ vs. $25 \%$ ). Steep declines between 1988 and 1999 were also noted in percentage of teachers that supported teaching about birth control (5) There is also reluctance for open discussion of reproductive health and ways to avoid consequences of sex in schools and in the media. Also contributing is the fact that large amounts of government monies are directed toward implementation of such programs, despite evidence to support the failure of such education to lower sexual risk-taking behaviors in adolescents (6). The belief that sex education, other than abstinence-only education, spurs adolescents to initiate sexual activity has not been supported in the medical literature $(7-10)$.

\section{ROLE OF THE ADOLESCENT}

In order to understand what interventions may best reach teenagers and encourage them to adopt abstinence, delay of sexual debut, or at the very least arm them with accurate medical information about sex, we must first understand the skills that adolescents are trying to accomplish during these years. Physically, they double their weight and may gain $25 \%$ in height, a growth spurt only exceeded in infancy (II). From a cognitive standpoint, most teens are capable of sequential logical thinking by age 16 years, the final adult stage of cognitive development (12). They can reproduce and can cause injury and death both to themselves and others. They are trying to establish independence from their parents, establish relationships with peers, finish school, and prepare for a job. It is a time of opposites: intense idealism versus extreme self-centeredness (11). It is a time when the peer group is valued over all others and a critical attitude is adopted towards established social norms. But it does not by nature have to be a difficult time.

There is currently great debate in the psychological literature about Hall's "storm and stress" theory of adolescence $(11,13)$. He theorized that conflict between parents and teens, mood disruption, and more risktaking behavior characterize this difficult time. Others feel that adolescence by nature is not a stressful, stormy time, but merely is viewed as such by Westem civilization. where there is no formal "rite of passage." A study by Offer et al found that most ieens $(80 \%)$ go through adolescence with minimal difficulty, and that teens have the same rate of behavior disturbance as people in other parts of the life cycle (14). Still, the apparent or real problems of individual adolescents should not be underestimated.

\section{ROLE OF SCHOOLS}

Sex education programs have been available in the schools and communjties for decades in the United States. In the 2001 Youth Risk Behavior Survey, $89 \%$ of teenagers report being exposed to HIV education in school. In the 1997 YRBS, $91 \%$ had reported being exposed to some from of sex education in school (15). Schools are likely to teach some aspects of reproductive health, but the content of such material can vary widely. In fact, the content of school sex education programs has not been studied since $1989(11,16)$. The question is: what should be raught and what works?

The US govemment currently favors abstinence-only education programs, with 59 million dollars per year for the last five years allocated to such programs (II). Literature review shows that studies of five abstinence-only programs failed to show significant delay of intercourse (17). Another review by DiCenso including 26 
trials showed that prevention strategies aimed at delay of intercourse, improvement of birth control use, and reducing unintended pregnancy rate did not achieve any of these goals. The same review found that four abstinence programs and one schoolbased sex education program were associated with an increased number of pregnancies among partners of young male participants (18). Fewer pregnancies occurred in young women who had received comprehensive sex education. It seems, therefore, that abstinence-only programs not only fail to demonstrate that less teens will become sexually active, but that they might carry an additional risk of increased pregnancy rates among maleparticipants' partners, presumably because the male is not armed with appropriate contraceptive knowledge. One recent study in JAMA showed that young people in an abstinence-only program, when compared to a safe sex program and a control group, were less likely to have had sex three months after the end of the program, but the difference disappeared after three months. From this, the authors conclude that both program types (abstinence and safe sex) can reduce sexual risk-taking behaviors, but that safe sex education might have a longer lasting effect (9).

Comprehensive sexual education programs seem to have more promise for actual intended results (delay of intercourse, increased contraceptive use). According to a literature review by Kirby, 6 of 16 studies found that comprehensive sex education programs (including information about contraception, STI's, and abstinence) can delay sexual debut. Another review of 30 studies of sexuality and HIV education programs found that these clearly do not increase any measure of sexual activity, but some do reduce sexual risk-taking behavior by delaying or decreasing sexual behavior or increasing condom use (17). Studies of programs teaching specifically HIV/AIDS related issues showed no increase in rates of sexual activity or earlier age of intercourse (11).

Schools start sex education at different grade levels/ages. There is little national data on the timing and content of sex education beginning in elementary schools in the US. A 1999 study showed that $72 \%$ of fifth and sixth grade teachers reported that sex education was taught in their school at one or both grades. The subjects most likely to be covered in this grade are pubertal changes, HIV and AIDS, how alcohol and drugs affect behavior and how to resist pressure regarding sexuality, and abstinence (19). However, when one looks at those numbers, a significant proportion of schools are not preparing students at this grade level for puberty or for dealing with issues regarding sexual activity, and many students are not receiving accurate information on topics their teachers feel they need (5). More data about timing of sex education in the schools is produced in countries other than the US. A study from England showed the median age of first sex education was 11 and that the majority of students believed this was appropriate timing, but that one-third believed it was too late (20). One study of Korean adolescents' view of school-based sex education shows that they feel it should start in elementary school (21).

Research on the adolescent's perspective on school sex education reveals that they see a role for abstinence promotion, but they do not think it should be the only intervention taught, as at some point many will want to initiate a sexual relationship (22). Adolescents also feel that sex education is often taught in the school by teachers with whom they felt uncomfortable discussing sexual issues (23). In one study using an anonymous health questionnaire from 955 adolescents at secondary schools in Spain (24), information about AIDS was viewed as the most sufficient in the sex 
education curriculum (by over $50 \%$ of participants). They report being able to talk openly about sexuality primarily with friends $(90.8 \%)$. They would prefer to receive sexual information first from parents (34\%), and then doctors (33\%).

\section{ROLE OF THE MEDIA}

The amount of sex that adolescents are exposed to in television, movies, advertising and other media is astounding. In a survey from Princeton Research Associates on sources of sexual information, $39 \%$ of teens reported the media as a source (3). This is no surprise, since the average teen spends almost 25 hours/week watching television alone, with music videos, VCR movies, and video games adding an average of 28 hours (3). This is far more time than they spend in the classroom.

Many television shows portray early sexual activity or sexual activity as normative, without delving into consequences such as pregnancy or STI's or use of contraception. In one year the average American teenager sees 14,000 sexual references on television (25). In one content analysis of prime-time shows, twothirds contained sexual content, but only $9 \%$ made mention of associated risks and responsibilities (26). Clearly, the media plays an important, but not always accurate or positive, role in providing adolescents with sexual information. Only a handful of studies, however, have examined the issue of media influence on earlier sexual intercourse or development of beliefs about sex (3), all more than ten years old. Some data now suggest that $10 \%$ to $30 \%$ of adolescent violence, sex, and drug use could be attributable to media influence (3).

\section{ROLE OF PARENTS}

The importance that teens place on their peer group has already been mentioned. No clear relationship between greater parent to adolescent communication and less adolescent risk-taking behavior is proven in the literature, but both adults and teens feel it is important (6). Blake studied the effect of parent-child communications combined with a school-based abstinence-only curriculum in middle school students and found that immediately after the intervention period fewer teens reported intention to have sex before finishing high school (27). This supports the notion that parent-child interaction reinforcing schoolbased prevention curricula can have an impact on sexual behavior among the age group studied. Another study of rural US parents found that $94 \%$ had talked to their teens about sex, including the responsibilities of parenthood, STI's, dating behavior, and abstinence. $80 \%$ beljeved that the family should provide sex education, with supplementation by schools. Almost all (92\%) believed sex education should include information on birth control methods, including condoms. Two-thirds thought school-based sex education should begin before seventh grade (28).

\section{ROLE OF HEALTH PROFESSIONALS}

Despite being cited as a preferted source of information on sexual issues $(24,29)$, teens receive little information from health care professionals. Teachers, school nurses, or classes at school rank tops $(40 \%)$ in a survey assessing sources of sexual information for teenagers (11), likely because a majority of teens are exposed to some form of sex education in school. Physician or nurse ranks at the bottom of the list at only $9 \%$. In short, the source teens cite as one of the most preferred (physicians) is either the least accessible or doing a poor job of discussing sexuality-related topics during routine health examinations. A 1999 study assessing provision of sex education by health professionals working in schools found mixed reactions from the teens: some liked the frankness with which the medical 
personnel dealt with sexual issues and the confidentiality they perceived with that. However, boys responded more negatively to this than girls, and differences in levels of development also played a key role in students' reactions (30).

\section{ROLE OF THE FUTURE}

Some studies may provide information on how to create more effective sex education programs that could be implemented in the schools, either alone or in combination with community, parent, or peer-led programs. One such study, the National Longitudinal Study on Adolescent Health, showed that parent-family connectedness and perceived school connectedness were protective against almost all risk-taking behaviors except pregnancy (11). This concept of strong family connections and resilient teens needs further attention in studies about designing successful sex-education programs. Creating greater resiliency through empowerment and increased selfefficacy is the principal behind one study on community service combined with classroom sex education that shows potentially promising results (positive. impact on the sexual behavior of young adolescents at risk for HIV, STl's, and unintended pregnancy) (31). Results from comparisons of peer-led versus adult-led sex education indicate that the peer leaders appear to be more effective in establishing attitudes about sexual behavior than adults, but less adept at giving factual information $(32,33)$. There are many peer-led, schoolbased sex education programs in the US, but not much evaluation of them in the literature (32). More research into the effectiveness of such programs is needed.

Finally, we may turn to models from other countries that are designed to help raise awareness of sexual and reproductive health outcomes. One such model developed in Canada is called "Pro-action, Postponement and Preparation/Support: $A$
Framework for Action to Reduce the Rate of Teen Pregnancy in Canada" (34). While targeting reduction in pregnancy, its principles of pro-action (creating resiliency in disadvantaged youth by strengthening competence, coping and problem solving skills), postponement (delay of first intercourse and decreased rate of unprotected intercourse), and preparation (help teens to maximize their knowledge of sex and its outcomes, including pregnancy) could certainly be applied to sex education programs.

\section{CONCLUSION}

Sex education remains controversial today, as it did when first instituted in the schools. Medical literature seems bent on continuing to try to dispel the same old myths "if you talk to teens about sex, they will only have sex"; "if you give them information and access to birth control, you allow them to have sex without the consequences," despite the fact that these concepts have been repeatedly disproved.

In the United States, our society promotes free sexual intercourse on a daily basis in the media without significantly portraying its risks, yet we continue to fall far behind other Western countries in our commitment to comprehensive sex education in our schools (3). Given the weight of available evidence in the literature showing possible delay of initial sexual activity and definite increased knowledge of and use of birth control methods, it seems high time to start implementing more comprehensive sex education programs in the schools, where the greatest percentage of teenagers have exposure.

As evidenced in the literature, support and supplementation of school programs by parents and health care professionals can enhance chances of successful postponement of sexual debut. We must recognize the need to educate our teenagers about contraception and increase the availability 
of contraception for teens. Our schools play a most valuable role in reaching our teens and teaching them about sex, if they are allowed to teach comprehensively.

\section{REFERENCES}

1. American Academy of Pediatrics. Committee on school health. School health assessments. Pediatrics 2000; 105(4):875-7.

2. Klerman LV. Adolescent pregnancy in the United States. Int J Adolesc Med Health $2002 ; 14(2): 91-6$.

3. Strasburger V, Donnerstein E. Children, Adolescents, and the Media: Issues and Solutions. Pediatrics 1999; 103(1): 129-39.

4. Centers for Disease Control. Youth risk behavior surveillance-United States, 2001. MMWR 51:(No. SS-4), 2002

5. Darroch JE, Landry DJ, Singh, S. Changing emphases in sexuality education in US public secondary schools, 1988-1999. Fam Plann Perspect 2000;32(5):204-11, 265.

6. Kirby D. Sexuality and sex education at home and school. Adolesc Med 1999;10(2):195-209.

7. Allen J. Editorial: Does abstinence make the heart grow fonder? Int J Adolesc Med Health 2002:14(2):8990.

8. Guttmacher $S$, Lieberman $L$, Ward D, Freudenberg N, Radosh A, DesJoulais D. Condom availability in New York City public high schools: relationships to condom use and sexual behavior. Am J Public Health 1997;87(9):142733.

9. Jemmott JB, Sweet Jemmott L, Fong GT, Abstinence and safer sex HIV risk-reduction interventions for African American adolescents: A randomized controlled trial. JAMA 1998;279(19):1529-36.

10. Kirby D, Brener ND, Brown NL,
Peterfreud N, Hillard P, Harsist R. The impact of condom availability in Seattle schools on sexual behavior and condom use. Am J Public Health 1999;89(2):182-7.

11. Strasburger V. Getting teenagers to say no to sex, drugs, and violence in the new millennium. Med Clin North Am 2000;84(4);787-810.

12. Piaget $\mathrm{J}$. Intellectual evolution from adolescence to adulthood. Ilum Dev 1972;15:1.

13. Arnett JJ. Adolescent storm and stress, reconsidered. Am Psychal 1999; 54: 317.

14. Offer D, Ostrov E, lloward Kl. Adolescence: What is normal? Am J Dis Child 1989;143:731.

15. Centers for Disease Control. Youth risk behavior surveillance, United States, 1997. MMWR 1998;47:1.

16. Forrest JD, Silverman J. What public school teachers teach about preventing pregnancy, AIDS, and sexually transmitted diseases. Fam Plan Perspect 1989;21:65.

17. Kirby C. Sexuality and sex education at home and school. Adolesc Med State Art Rev 1999;10:195.

18. DiCenso $A$. Interventions to reduce unintended pregnancies among adolescents: a systematic review of randomized controlled trials. BMJ 2002; 324:1426.

19. Landry DJ, Singh S, Darroch JE. Sexuality education in fifth and sixth grades in U.S. public schools, 1999. Fam Plan Perspect 2000; 32(5):212-9.

20. Ogden J. The timing, format and content of school based sex education: an experience with a lasting effect? $\mathrm{Br}$ J Fam Plann 1999;35(3)115-8.

21. Seung-Duk K, Eun-Joo K, Hye-Kyung $S$, Aeree S. Viewpoints of Korean senior high school students on schoolbased sex education. Asia Pac J Public Health 2001;12(Suppl): S31-5. 
22. Aquilano $\mathrm{ML}$, Bragadottir $\mathrm{H}$.
Adolescent pregnancy: Teen perspectives on prevention. Am J Matern Child Nurs 2000; 25(4):192-7.

23. DiCenso A. Completing the picture: adolescents talk about what's missing in sexual health services. Can J Public Health. 2001; 92(1):35-8.

24. Romero-de-Castilla-Gil RJ, LoraLerenzo $\mathrm{MN}$, Canete-Estrada $\mathrm{R}$. Adolescents and sources of sex information: preferences and perceived usefulness. Aten Primaria. 2001 Jan; $27(1): 12-7$.

25. Harris L. Sexual material on American network television during the 1987-88 season. New York, Planned Parenthood Federation of America, 1988.

26. Kunkel D, Cope KM, Farinola WJM, Biely E, Rollin E, Donnerstein E. Sex on TV: Content and Context. Santa Barbara, CA: Henry J. Kaiser Family Foundation, 1999.

27. Blake SM. Effects of a parent-child communications intervention on young adolescents' risk for early onset of sexual intercourse. Fam Plan Perspect 2001;33(2):52-61.

28. Jordan TR, Price JH, Fitzgerald S. Rural parents' communication with their teen-agers about sexual issues. J Sch Health $2000 ; 70(8): 338-44$.
29. Thakor HG, Kumar P. Impact assessment of school-based - sex education program among adolescents. Indian J Pediatr 2000;67(8): 55158.

30. Measor L, Tiffin C, Miller K. Health professionals and the sex education of adolescents. Nurs Times 1999;95(21): 48-51.

31. O'Donnell L, Stueve A, San Dovel A, Duran A, Duran R, Haber P, et al. The effectiveness of the reach for health community youth service learning program in reducing early and unprotected sex among urban middle school students. Am J Public Health 1999;89:176-81.

32. Mellanby AR. A comparative study of peer-led and adult-led school sex education. Health Educ Res 2001; 16(4):481-92.

33. Strange V, Forrest S, Oakley A. Peerled sex education-characteristics of peer educators and their perceptions of the impact on them of participation in a peer education programme. Health Educ Res 2002; 17(3): 327-37.

34. Rogers BA, Dilworth MA. Reducing the rate of teen pregnancy in Canada: A framework for action. Int $\mathrm{J}$ Adolesc Med Health. 2002;14(2):97-100. 